\title{
DESIGN AND CHARACTERIZATION OF CHLORZOXAZONE FLOATING BIOADHESIVE DRUG DELIVERY SYSTEM
}

\author{
MANISH KUMAR PAL ${ }^{1 *}$, GANESH DESHMUKH ${ }^{2}$ \\ Department of Pharmaceutics, Oriental College of Pharmacy, Sanpada, Navi Mumbai - 400 705, Maharashtra, India. \\ Email: manishpal934@gmail.com
}

Received: 04 June 2018, Revised and Accepted: 05 July 2018

\section{ABSTRACT}

Objective: The objective of the work is to formulate chlorzoxazone floating bioadhesive tablets which will significantly improve the bioavailability of drugs under the condition of prolonged use of drugs and reduce the total dosage of administered drug and reduce the side effect.

Methods: Floating bioadhesive tablet was prepared by direct compression of polymer such as HPMCK4M and Carbopol934p in combination.

Result: After analysis of different evaluation parameter and drug release, F9 batch was selected as promising formulation for delivery of chlorzoxazone floating bioadhesive tablets with $92.1 \%$ drug release at $12^{\text {th }} \mathrm{h}$.

Conclusion: It was observed that the combination of polymers in $22.5 \%$ (HPMCK4M) and $12.5 \%$ (Carbopol 934p) give the best drug release and sustain the drug release for $12 \mathrm{~h}$. Among the other batches, F9 batch was selected as an optimized batch because the pre- and post-compression parameters results are satisfactory.

Keywords: Chlorzoxazone, Floating bioadhesive tablets, HPMCK4M, Carbopol 934p, Direct compression.

(C) 2018 The Authors. Published by Innovare Academic Sciences Pvt Ltd. This is an open access article under the CC BY license (http://creativecommons. org/licenses/by/4. 0/) DOI: http://dx.doi.org/10.22159/ajpcr.2018.v11i11.27693

\section{INTRODUCTION}

The design of oral modified release dosage form is intended to optimize a therapeutic regimen by providing controlled delivery of drug over the entire dosing interval. Among the various routes of administration oral intake have long been the most convenient and commonly employed route. There are many ways to intend modified release dosage forms for oral administration and one of them is floating bioadhesive tablets [1].

FBDS is a gastro-retentive dosage form, which can prolong the gastric residence time to produce an acceptable drug bioavailability. Floating bioadhesive drug delivery system (FBDDS) is suitable for drugs with an absorption window in the stomach or the upper small intestine, for drugs which act locally in the stomach and for drugs that are poorly soluble or unstable in the intestinal fluid FBDDS or hydro-dynamically balanced systems have a bulk density lower than gastric fluid and thus remain buoyant in the stomach without affecting the gastric emptying rate for a prolonged period of time. Based on the mechanism of buoyancy, two distinctly different technologies, i.e., non-effervescent and effervescent systems, have been used in the development of FBDDS.

The effervescent system uses matrices prepared with swellable polymers and effervescent components, for example, sodium bicarbonate and citric acid or stearic acid. In non-effervescent FBDDS, the drug mixes with a gel-forming hydrocolloid, which swells in contact with gastric fluid after oral administration to maintain a relatively stable shape and a bulk density of less than unity within the outer gelatinous barrier. The air trapped by the swollen polymer confers buoyancy on these dosage forms [2].

Chlorzoxazone(structure shownin Fig.1),(2-hydroxy-5-chlorobenzoxazole) is a Class-II drug low solubility, high permeability, a centrally acting central muscle relaxant with sedative properties. It is claimed to inhibit muscle spasm by exerting an effect primarily at the level of the spinal cord and subcortical areas of the brain [3].

\section{MATERIALS AND METHODS}

Chlorzoxazone was a procured from Yarochem, Mumbai. HPMCK4M were procured from Chemdyes Corporation, Gujarat. Carbopol 934p were procured from Research Lab-Fine Chem. Industries, Mumbai. Lactose, Sodium Bicarbonate, Magnesium stearate was procured from Thomas Baker Pvt. Ltd, Mumbai. All reagents used were of analytical grade.

\section{METHODS}

\section{Drug excipient compatibility studies}

Fourier-transform infrared (FT-IR) spectrum matching approach was used for detection of any possible chemical interaction between the chlorzoxazone and polymers. IR spectroscopy was conducted using a FTIR spectrophotometer (Jasco FT-IR 410), and the spectrum was recorded in the wavelength region of $4000-400 / \mathrm{cm}$. The procedure consisted of dispersing a sample (drug alone or mixture of drug and excipients) in $\mathrm{KBr}$ and compressed into discs by applying a pressure of 5 tons for $5 \mathrm{~min}$ in a hydraulic press. The pellet was placed in the light path, and the spectrum was obtained. Samples were prepared for chlorzoxazone, polymers such as Carbopol 934, HPMCK4M and physical mixture of drug with polymers. The spectra obtained were compared and interpreted for the functional group peaks [4].

\section{Preformulation studies}

Ultraviolet (UV)-spectrum of drug chlorzoxazone

The solution of chlorzoxazone in $0.1 \mathrm{~N}$ HCL screened in the range of $200-400 \mathrm{~nm}$.

\section{Melting point}

The melting point of the drug was determined using packing a capillary method.

\section{Physical properties of drug powder}

The drug chlorzoxazone undergoes through various tests to know its physical properties. 
Table 1: Composition floating bioadhesive tablet of chlorzoxazone prepared by direct compression

\begin{tabular}{|c|c|c|c|c|c|c|c|c|c|}
\hline Ingredient & F1 (mg) & F2 (mg) & F3 (mg) & F4 (mg) & F5 (mg) & F6 (mg) & F7 (mg) & F8 (mg) & F9 (mg) \\
\hline Chlorzoxazone & 300 & 300 & 300 & 300 & 300 & 300 & 300 & 300 & 300 \\
\hline HPMC K4M & 87.5 & 87.5 & 87.5 & 100 & 100 & 100 & 112.5 & 112.5 & 112.5 \\
\hline Carbopol 934p & 20 & 25 & 30 & 20 & 25 & 30 & 20 & 25 & 30 \\
\hline Sodium bicarbonate & 50 & 50 & 50 & 50 & 50 & 50 & 50 & 50 & 50 \\
\hline Mg. St. & 5 & 5 & 5 & 5 & 5 & 5 & 5 & 5 & 5 \\
\hline Lactose & 37.5 & 32.5 & 27.5 & 25 & 20 & 15 & 12.5 & 7.5 & 2.5 \\
\hline Total & 500 & 500 & 500 & 500 & 500 & 500 & 500 & 500 & 500 \\
\hline
\end{tabular}

\section{Construction of calibration curve}

The calibration curve for chlorzoxazone was determined in $0.1 \mathrm{~N} \mathrm{HCl} \mathrm{pH}$ 1.2 in UV spectrophotometer in Fig. 2.

The flow properties of granules were characterized in terms of angle of repose, Carr's index, Compressibility index, and Hausner's ratio. The bulk density and tapped density were determined, and from this data, Carr's index and Hausner's ratio were calculated [5].

\section{Formulation of floating bioadhesive tablet of chlorzoxazone}

Floating bioadhesive drug delivery of chlorzoxazone was prepared by direct compression method. The composition of formulations is shown in Table 1. All the powders were passed through a 60 mesh sieve. The required quantity of drug, polymers mixture and diluents were mixed. The powder blend was lubricated with magnesium stearate and compressed using (11.6 $\mathrm{mm}$ diameter punches) multiple punch rotary tablet machine. In total, 9 formulations containing different amounts of HPMCK4M and Carbopol934p combination were prepared.

\section{Characterization of matrix tablets}

\section{Thickness}

Selected randomly 5 tablets from each batch were used for thickness determination. The thickness of each tablet was measured in mm using a digital Vernier Caliper their values were reported in millimeters. The mean and standard deviation was calculated and reported.

\section{Weight variation test}

A total of 20 tablets were selected randomly from each batch and individually weighed using an electronic balance. The average weight was calculated. The percentage deviation from average weight was reported.

\section{Hardness}

The hardness of five tablets which randomly selected from each batch was measured using Monsanto hardness tester and expressed in $\mathrm{kg} / \mathrm{cm}^{2}$.

\section{Friability}

Five tablets were randomly selected from each batch and accurately weigh the tablet sample, and place the tablets in the drum. Rotate the drum 100 times, and remove the tablet re-weighed and percentage loss was determined. Friability of tablets was performed using Roche Friabilator.

\section{Drug content analysis}

Five tablets were weighed individually, and the average was calculated and grounded in a mortar with a pestle to get a fine powder. An amount equivalent to $300 \mathrm{mg}$ of the drug was extracted with $100 \mathrm{ml}$ of $0.1 \mathrm{~N}$ $\mathrm{HCl}$. The drug content was determined by UV spectrophotometer at a wavelength $282 \mathrm{~nm}$, and the percentage drug content was calculated.

\section{Swelling index}

The swelling of the mucoadhesive polymer is an important factor affecting adhesion. To carry out the study, a tablet was weighed and placed in a Petri dish containing $5 \mathrm{ml}$ of $0.1 \mathrm{~N}$ HCL buffer $\mathrm{pH} 1.2$ in $5 \mathrm{hrs}$ at regular interval of time $(1,2,3,4$, and 5$)$ the tablet was taken care by

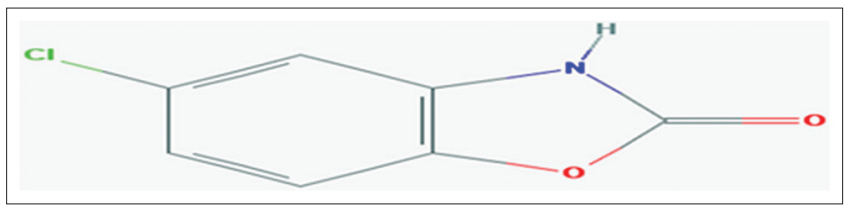

Fig. 1: Chlorzoxazone drug structure

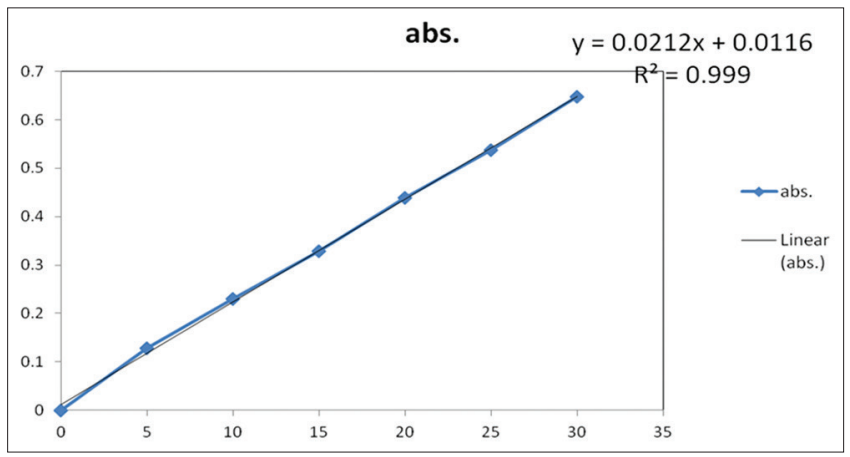

Fig. 2: Calibration curve of chlorzoxazone

using filter paper. The swelling index was calculated using the following formula,

Swelling index $=\mathrm{w}_{\mathrm{t}}-\mathrm{w}_{0} / \mathrm{w}_{0} \times 100$

Mucoadhesive strength measurement [6-9]

The mucoadhesive strength of the tablet was measured on the modified physical balance apparatus consists of a modified double beam physical balance in which the right and left pan has been replaced by lighter pans. The left side of the balance was made $5 \mathrm{~g}$ heavier than the right side by placing a $5 \mathrm{~g}$ weight on left side pan. Another Teflon block of 3.8 $\mathrm{cm}$ diameter and $2 \mathrm{~cm}$ height was fabricated with an upward portion of $2 \mathrm{~cm}$ height and $1.5 \mathrm{~cm}$ diameter on one side. This was kept in a beaker, which was then placed below the left-hand set of the balance.

The goat gastric mucosa was used as the model membrane, and $\mathrm{pH} 1.2$ was used as the moistening fluid. The goat gastric mucosa was kept in Tyrode solution at $37^{\circ} \mathrm{C}$ for $2 \mathrm{~h}$. The underlying mucous membrane was separated and washed thoroughly with a pH 1.2 solutions. It was then tied to a Teflon-coated glass slide, and this slide was fixed over the protrusion in the Teflon block using a thread. The block was then kept in a beaker containing $\mathrm{pH} 1.2$ buffer solutions at the level that just touches the membrane. By keeping a $5 \mathrm{~g}$ weight on the right pan, the two sides of the balance were made equal. The beaker with the Teflon block was kept below the left hand set up of the balances. The tablets of each batch were struck on to the lower side of the left-hand side pan. The $5 \mathrm{~g}$ weight from the right pan was then removed. This lowered the left pan along with the tablet over the membrane with a weight of $5 \mathrm{~g}$. This was kept undisturbed for $5 \mathrm{~min}$. Then, the weight on the righthand side was slowly added in an increment of $0.5 \mathrm{~g}$ till the tablet just separated from the membrane surface. The excess weight on the right pan, i.e., total weight $-5 \mathrm{~g}$ was taken as a measure of the mucoadhesive strength. 
From the mucoadhesive strength, the force of adhesion was calculated using the following formula:

$$
\text { Force of adhesion }(N)=\frac{\text { Bioadhesive strength }}{100} \times 9.81
$$

\section{In vitro buoyancy study [10]}

The in vitro buoyancy was determined by measuring floating lag time and duration of buoyancy. The tablets were placed in a $100 \mathrm{ml}$ beaker containing $100 \mathrm{ml}$ of $0.1 \mathrm{~N} \mathrm{HCl}$. The time required for the tablet to rise to the surface and float was taken at the floating lag time. The time for which tablets kept floating was termed as "buoyancy time" of the tablets which were determined for all the formulations.

\section{In vitro drug release study}

In vitro, drug release studies were performed using the USP dissolution apparatus Type-II. The drug release profile was studied in $900 \mathrm{ml}$ of $0.1 \mathrm{~N} \mathrm{HCl}$ buffer of pH 1.2 at $37 \pm 0.2^{\circ} \mathrm{C}$. The rotational speed of the paddle was $50 \mathrm{RPM}$. Aliquots of $5 \mathrm{ml}$ of dissolution medium were withdrawn at specific time intervals, filtered and replaced with fresh medium. The samples were filtered through Whatman filter paper and analyzed after appropriate dilution by a UV spectrophotometer (Shimadzu UV 1800) at $282 \mathrm{NM}$, and drug release was determined from the standard curve.

\section{Statistical analysis}

To evaluate the contribution of each factor with different levels on responses, two-way analysis of variance (ANOVA) was performed using GraphPad Prism 7.04 Software.

\section{RESULTS AND DISCUSSION}

\section{Drug excipient compatibility studies}

The results showed that the principle IR peak of pure drug, its physical mixture with polymer was almost similar, signifying no interaction between drug and polymer during formulation of tablets.

\section{UV-spectrum of drug chlorzoxazone}

The solution of chlorzoxazone in 0.1N HCL was found to exhibit maximum absorption $\left(\lambda_{\max }\right)$ at $282 \mathrm{~nm}$ after scanning in the range of 200-400 nm. As shown in Fig. 3.

\section{Physical properties of drug powder}

The drug chlorzoxazone undergoes through various tests to know its physical properties Table 2 .

\section{Preformulation studies of powders}

The prepared powders were characterized for angle of repose, bulk density, tapped density, Hausner's factor, Carr's index, and compressibility index and the values were reported in Table 3. The angle of repose of the different batches of powders was determined as per the method mentioned earlier, and the results ranged between $20.005^{\circ}$ and $24.38^{\circ}$. The powder with the angle of repose $<20^{\circ}$ indicates excellent flow properties. The bulk densities of powder were ranged between $0.25 \mathrm{~g} / \mathrm{cm}^{3}$ and $0.33 \mathrm{~g} / \mathrm{cm}^{3}$. The low bulk density is due to the presence of more fines in the powder. Tapped density ranged between $0.303 \mathrm{~g} / \mathrm{cm}^{3}$ and $0.4 \mathrm{~g} / \mathrm{cm}^{3}$.

\section{Evaluation of bioadhesive floating tablet}

Weight variation, thickness, hardness, friability, and drug content analysis

The results were represented in Table 4. The diameters of prepared tablets were ranged from 11.98 to 12.003 . The weights of prepared tablets were ranging from $488.1 \pm 24.40$ to $494.2 \pm 24.71$. The thickness of prepared tablets ranged from 4.08 to 4.48 . It was also observed that increasing the polymer concentration resulted in a slight decrease in the thickness of tablet formulations. These results indicate that the polymers may have high binding properties. Hardness of tablet ranged from 5.16 to $7.34 \mathrm{~kg} / \mathrm{cm}^{2}$. For all formulation, friability ranged from 0.0 to $0.7 \%$ it indicating that friability is within the prescribed limit
Table 2: Physical properties of drug powder

\begin{tabular}{lll}
\hline Sr. No & Test & Result \\
\hline 1 & Bulk density $(\mathrm{g} / \mathrm{ml})$ & 0.433 \\
2 & Tap density $(\mathrm{g} / \mathrm{ml})$ & 0.534 \\
3 & Carr's compressibility & $19 \%$ \\
4 & Hausner's ratio & 1.23 \\
5 & Angle of repose & $30^{\circ}$ \\
& Flow properties & Passable \\
\hline
\end{tabular}

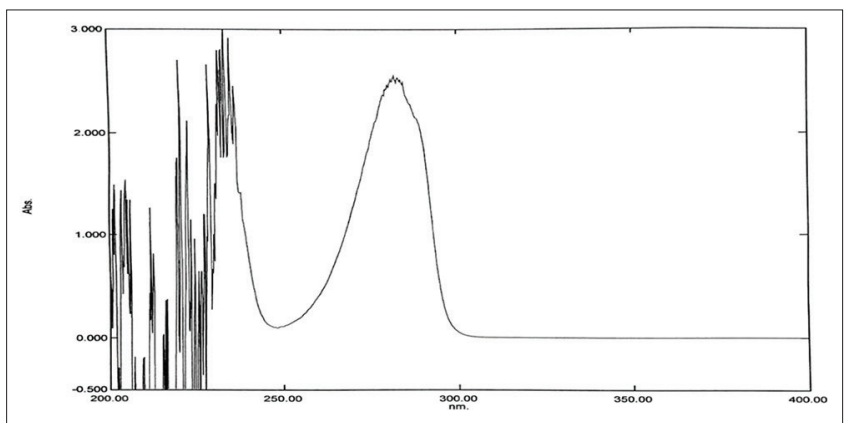

Fig. 3: Ultraviolet spectrum of chlorzoxazone

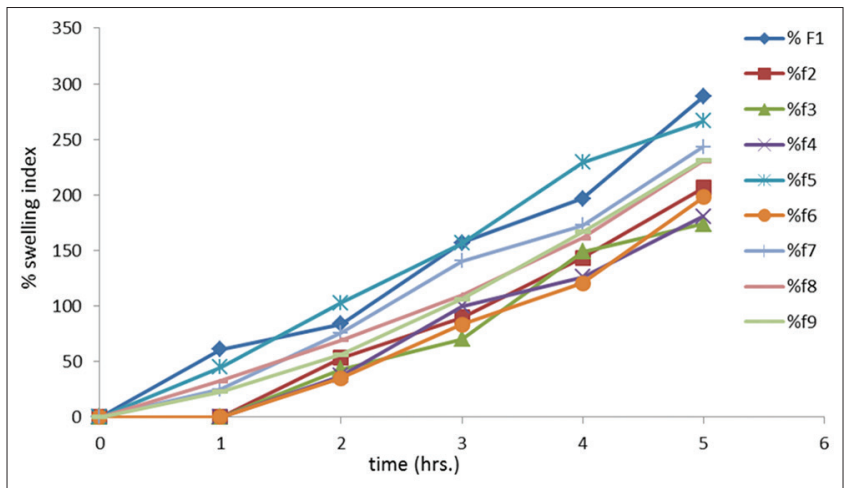

Fig. 4: Swelling index studies of floating bioadhesive tablets

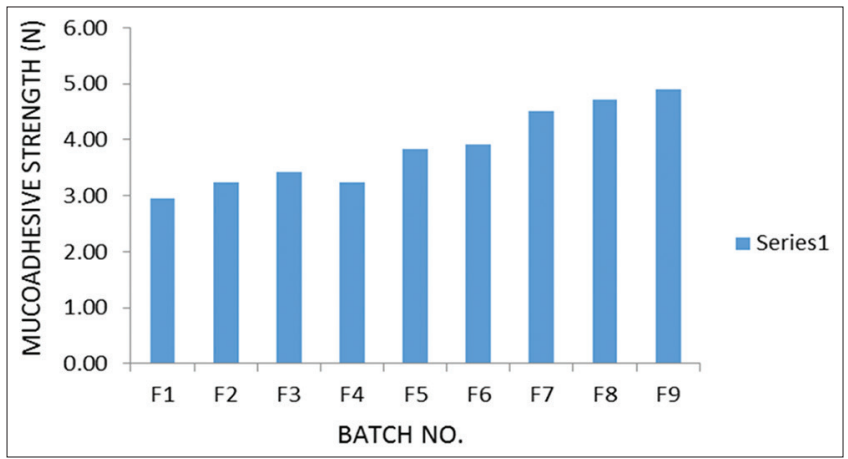

Fig. 5: Bioadhesive strength of a tablet

of $1 \%$. The drug content (\%) of floating bioadhesive tablet from each formulation was found to be uniform and ranged from 93.99 to $96.98 \%$.

\section{Swelling studies}

Swelling index profile of all formulations is shown in Table 5 and Fig. 4. Swelling index of all formulations is varies between 230.61 and $288.36 \%$. Swelling of the matrix, this is indicated by the transition of the polymer from the glassy to the rubbery state. It is an important parameter in determining the release characteristics of the matrix system. As swelling process proceeds, the gel layer gradually becomes thicker, and therefore the drug concentration gradient along the diffusional path length is decreased results in the slow drug release. 
Table 3: Pre-compression parameter of blend

\begin{tabular}{|c|c|c|c|c|c|c|}
\hline Batches & $\begin{array}{l}\text { Bulk density } \\
(\mathrm{g} / \mathrm{ml})\end{array}$ & $\begin{array}{l}\text { Tapped density } \\
(\mathrm{g} / \mathrm{ml})\end{array}$ & $\begin{array}{l}\text { Compressibility } \\
\text { index }(\%)\end{array}$ & $\begin{array}{l}\text { Hausner's } \\
\text { ratio }\end{array}$ & $\begin{array}{l}\text { Carr's } \\
\text { index }(\%)\end{array}$ & $\begin{array}{l}\text { Angle of } \\
\text { repose (degree) }\end{array}$ \\
\hline F1 & 0.33 & 0.4 & 16.66 & 1.21 & 18 & 20.005 \\
\hline $\mathrm{F} 2$ & 0.303 & 0.384 & 21.21 & 1.267 & 22 & 23.85 \\
\hline F3 & 0.277 & 0.344 & 19.44 & 1.515 & 20 & 21.55 \\
\hline F4 & 0.294 & 0.344 & 14.70 & 1.12 & 14.6 & 21.31 \\
\hline F5 & 0.25 & 0.33 & 25 & 1.32 & 25 & 21.75 \\
\hline F6 & 0.25 & 0.312 & 20 & 1.248 & 19.9 & 21.44 \\
\hline F8 & 0.263 & 0.303 & 13.5 & 1.152 & 13.3 & 24.38 \\
\hline F9 & 0.277 & 0.33 & 16.66 & 1.19 & 17 & 21.75 \\
\hline
\end{tabular}

Table 4: Tablet evaluation

\begin{tabular}{|c|c|c|c|c|c|c|}
\hline $\begin{array}{l}\text { Formulation } \\
\text { code }\end{array}$ & $\begin{array}{l}\text { Diameter* } \\
\text { (mm) }\end{array}$ & $\begin{array}{l}\text { Thickness* } \\
\text { (mm) }\end{array}$ & $\begin{array}{l}\text { Hardness* } \\
\left(\mathrm{kg} / \mathrm{cm}^{2}\right)\end{array}$ & Friability (\%) & $\begin{array}{l}\% \text { Weight } \\
\text { variation }^{\wedge}\end{array}$ & $\begin{array}{l}\text { \% drug } \\
\text { content* }\end{array}$ \\
\hline F1 & $11.98 \pm 0.005$ & $4.18 \pm 0.036$ & $5.16 \pm 0.288$ & 0 & $492.4 \pm 24.62$ & $93.99 \pm 0.00$ \\
\hline $\mathrm{F} 2$ & $11.99 \pm 0.005$ & $4.08 \pm 0.011$ & $5.33 \pm 0.288$ & 0.7 & $493.5 \pm 24.67$ & $94.86 \pm 0.375$ \\
\hline F3 & $11.99 \pm 0.005$ & $4.32 \pm 0.034$ & $5.5 \pm 0.00$ & 0.5 & $491.8 \pm 24.59$ & $96.56 \pm 0.640$ \\
\hline F4 & $12.003 \pm 0.005$ & $4.40 \pm 0.02$ & $6 \pm 0.00$ & 0.6 & $493.9 \pm 24.69$ & $96.56 \pm 0.640$ \\
\hline F5 & $12.003 \pm 0.005$ & $4.48 \pm 0.011$ & $6.16 \pm 0.288$ & 0 & $493.2 \pm 24.66$ & $95.07 \pm 0.375$ \\
\hline F6 & $12 \pm 0.017$ & $4.48 \pm 0.015$ & $6.16 \pm 0.288$ & 0.6 & $489.6 \pm 24.48$ & $95.93 \pm 0.00$ \\
\hline F8 & $11.98 \pm 0.01$ & $4.3 \pm 0.026$ & $7.16 \pm 0.288$ & 0.7 & $488.1 \pm 24.40$ & $96.77 \pm 0.416$ \\
\hline F9 & $11.99 \pm 0.02$ & $4.32 \pm 0.01$ & $7.34 \pm 0.288$ & 0 & $494.2 \pm 24.71$ & $96.98 \pm 0.393$ \\
\hline
\end{tabular}

*All values expressed in mean $\pm S D, n=3$, ^all value expressed in mean $\pm S D, n=10$. SD: Standard deviation

Table 5: Swelling index studies of floating bioadhesive tablets

\begin{tabular}{|c|c|c|c|c|c|c|c|c|c|}
\hline Time & $\%$ F1 & $\%$ F2 & $\%$ F3 & $\%$ F4 & \%F5 & $\%$ F6 & $\%$ F7 & $\%$ F8 & $\%$ F9 \\
\hline 0 & 0 & 0 & 0 & 0 & 0 & 0 & 0 & 0 & 0 \\
\hline 1 & 61.22 & 53.60 & 43.15 & 37.37 & 44.92 & 35.41 & 25.25 & 32.65 & 22.91 \\
\hline 2 & 83.67 & 89.69 & 70.12 & 100.00 & 102.89 & 83.33 & 75.75 & 69.38 & 56.25 \\
\hline 3 & 157.14 & 143.29 & 148.96 & 126.26 & 156.72 & 120.83 & 140.40 & 110.20 & 106.25 \\
\hline 4 & 196.93 & 206.59 & 173.85 & 180.80 & 229.19 & 197.91 & 172.72 & 161.22 & 166.67 \\
\hline 5 & 288.36 & 283.50 & 263.07 & 261.61 & 266.45 & 264.58 & 243.43 & 230.61 & 231.25 \\
\hline
\end{tabular}

Table 6: Bioadhesive strength of a tablet

\begin{tabular}{lll}
\hline Batch no. & Bioadhesive strength $\mathbf{( g )}$ & Bioadhesion force (N) \\
\hline F1 & 30 & 2.94 \\
F2 & 33 & 3.24 \\
F3 & 35 & 3.43 \\
F4 & 33 & 3.24 \\
F5 & 39 & 3.83 \\
F6 & 40 & 3.92 \\
F7 & 46 & 4.51 \\
F8 & 48 & 4.71 \\
F9 & 50 & 4.91 \\
\hline
\end{tabular}

Table 7: Floating lag time

\begin{tabular}{lll}
\hline Batch no. & Floating lag time $(\mathbf{s})$ & Total floating time $(\mathbf{h})$ \\
\hline F1 & $10 \pm 0.5$ & $>12$ \\
F2 & $11 \pm 0.5$ & $>12$ \\
F3 & $13 \pm 0.5$ & $>12$ \\
F4 & $12 \pm 1.5$ & $>12$ \\
F5 & $24 \pm 2$ & $>12$ \\
F6 & $27 \pm 1.15$ & $>12$ \\
F7 & $22 \pm 4.6$ & $>12$ \\
F8 & $17 \pm 1.15$ & $>12$ \\
F9 & $22 \pm 2$ & $>12$ \\
\hline
\end{tabular}

\section{Measurement of bioadhesion force}

The mucoadhesive strength of the tablet was dependent on the property of the bioadhesive polymers, which on hydration adhere to the mucosal

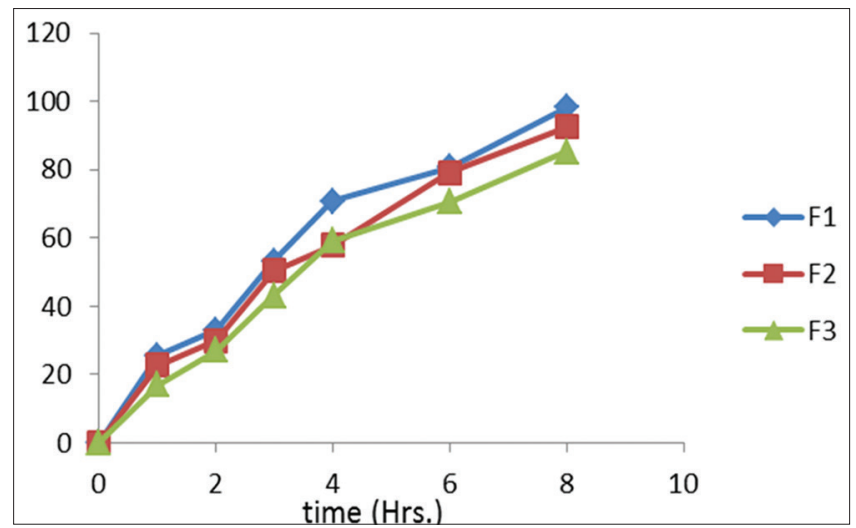

Fig. 6: In vitro drug release profile of batches (F1-F3)

surface and also on the concentration of polymer used. Bioadhesive force values ranged from 2.94 to 4.91 . Results were represented in Table 6 and Fig. 5.

In vitro buoyancy study

Floating lag time of all nine batches shown in Table 7.

In vitro dissolution studies

All the nine formulations were subjected to in vitro dissolution studies using a USP Type-II dissolution test apparatus. The dissolution medium 
Table 8: In vitro dissolution study of tablets

\begin{tabular}{|c|c|c|c|c|c|c|c|c|c|}
\hline Time (h) & F1 & F2 & F3 & F4 & F5 & F6 & F7 & F8 & F9 \\
\hline 0 & $0 \pm 0$ & $0 \pm 0$ & $0 \pm 0$ & $0 \pm 0$ & $0 \pm 0$ & $0 \pm 0$ & $0 \pm 0$ & $0 \pm 0$ & $0 \pm 0$ \\
\hline 1 & $25.33 \pm 0.05$ & $22.52 \pm 0.01$ & $16.61 \pm 0.17$ & $15.57 \pm 0.27$ & $8.32 \pm 0.10$ & $6.66 \pm 0.32$ & $6.63 \pm 0.29$ & $6.6 \pm 0.27$ & $3.86 \pm 0.14$ \\
\hline 2 & $32.72 \pm 0.15$ & $30.07 \pm 0.09$ & $27.10 \pm 0.04$ & $21.33 \pm 0.21$ & $21.32 \pm 0.21$ & $18.36 \pm 0.21$ & $16.55 \pm 0.40$ & $14.26 \pm 0.26$ & $9.48 \pm 0.31$ \\
\hline 3 & $53.14 \pm 0.15$ & $50.03 \pm 0.23$ & $43.23 \pm 0.29$ & $47.32 \pm 0.22$ & $32.66 \pm 0.18$ & $35.61 \pm 0.09$ & $29.69 \pm 0.24$ & $35.6 \pm 0.08$ & $24.42 \pm 0.22$ \\
\hline 4 & $70.70 \pm 0.17$ & $57.52 \pm 0.36$ & $59.31 \pm 0.40$ & $57.47 \pm 0.33$ & $55.98 \pm 0.16$ & $53.35 \pm 0.38$ & $50.38 \pm 0.36$ & $41.51 \pm 0.35$ & $37.38 \pm 0.36$ \\
\hline 6 & $80.48 \pm 0.23$ & $79.76 \pm 0.55$ & $70.21 \pm 0.23$ & $73.15 \pm 0.15$ & $67.20 \pm 0.23$ & $64.24 \pm 0.24$ & $58.32 \pm 0.42$ & $58.31 \pm 0.41$ & $55.32 \pm 0.42$ \\
\hline 8 & $98.21 \pm 0.04$ & $92.62 \pm 0.42$ & $85.16 \pm 0.06$ & $83.37 \pm 0.29$ & $73.65 \pm 0.47$ & $73.75 \pm 0.35$ & $74.51 \pm 0.34$ & $71.54 \pm 0.40$ & $67.4 \pm 0.20$ \\
\hline 12 & - & - & - & - & - & - & $87.41 \pm 0.26$ & $88.53 \pm 0.12$ & $92.1 \pm 0.77$ \\
\hline
\end{tabular}

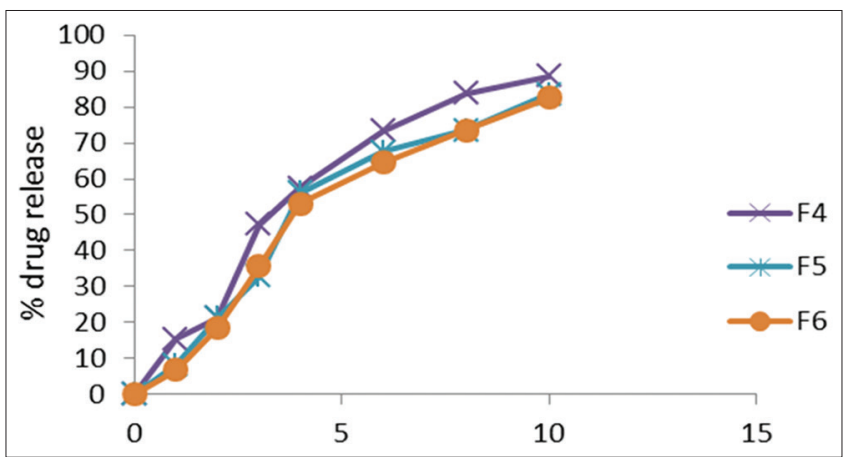

Fig. 7: In vitro drug release profile of batches (F4-F6)

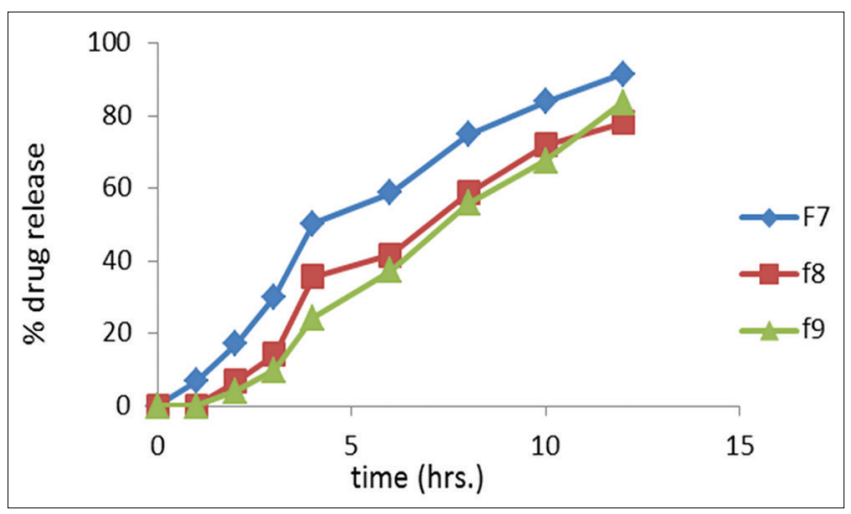

Fig 8: In vitro drug release profile of batches (F7-F9)

$1.2 \mathrm{pH}$ buffer was used to study the drug release. The samples were withdrawn at different intervals of time and analyzed at $282 \mathrm{NM}$ using a UV spectrophotometer. The cumulative percentage drug release was calculated. The data obtained from in vitro release for formulations prepared by direct compression technique are tabulated in Table 8 .

In vitro dissolution studies of nine batches that the batch F1, F2, and F3 tablets completely disintegrated at $8 \mathrm{~h}$ (Fig. 6) and batch F4, F5, and F6 completely disintegrated at $10 \mathrm{~h}$, so these batches were rejected (Fig. 7). Among the other batches, F7, F8, and F9 batches were completely disintegrated at $12 \mathrm{~h}$ (Fig. 8).

\section{CONCLUSION}

Floating mucoadhesive tablet of chlorzoxazone was prepared by direct compression method using a polymer such as HPMC K4M, Carbopol 934p, and other excipients. All pre- and post-compression study was done in all nine batches of the tablet. In vitro dissolution studies of nine batches concluded that the batch F1, F2, and F3 tablets completely disintegrated at $8 \mathrm{~h}$ and batch F4, F5, and F6 completely disintegrated at $10 \mathrm{~h}$, so these batches were rejected. Among the other batches, F9 batch was selected as an optimized batch because the pre- and postcompression parameters results are satisfactory. The F9 batch showed that the best result as the percent cumulative drug release of F9 is $91.22 \%$ at $12 \mathrm{~h}$.

\section{ACKNOWLEDGMENTS}

Authors are thankful to Prof. (Dr.) Mrs. Sudha Rathod, Principal of Oriental College of pharmacy, Sanpada, Navi Mumbai, India, provides all the facilities for this research Project.

\section{AUTHORS CONTRIBUTION}

We declare that this work was done by the authors named in this article and all liabilities pertaining to claims relating to the content of this article will be borne by the authors. Mr. Manish Kumar Pal collected the data, analyzed the data, all the laboratory work performed, wrote the introduction, discussion and the material and method part. Dr. Ganesh Deshmukh proof-read the whole manuscript as well as helps in designing and conducting the study.

\section{CONFLICTS OF INTEREST}

The authors declare that there are no conflicts of interest regarding the publication of this paper.

\section{REFERENCES}

1. Ahmeda SI, Mangamoorib LN, Raoc YM. Formulation and characterization of matrix and triplelayer matrix tablets for oral controlled drug delivery. Int J Pharm Pharm Sci 2010;2:137-43.

2. Shivprashad BM, Jagdeep DD, Development and evaluation of floating-mucoadhesive dipyridamole tablet. Asian J Pharm Res Health care 2012;4:78-89.

3. National Center for Biotechnology Information. PubChem Compound Database; $C I D=2733$, Available from: https://pubchem.ncbi.nlm.nih. gov/compound/2733. [last accessed on $2018 \mathrm{Jul} 26$ ].

4. Shaikh AC, Nizam S, Siraj S, Khan T, Patel MS, Zameeruddin M, et al. Formulation And evaluation of sustained release tablets of aceclofenac using hydrophilic matrix system. Int J Pharm Pharm Sci 2011;3:145-8.

5. Charyulu NR, Patel K, Jose J. Formulation and evaluation of acyclovir matrix tablet using mucoadhesive polymer. J Drug Deliv Ther 2013;3:52-7

6. Singh $\mathrm{S}$, Govind $\mathrm{M}$, Bothara $\mathrm{SB}$. A Review on in vitro-in vivo mucoadhesive strength assessment. Pharm Tech Medica 2013;2:221-7.

7. Tangri P, Madhav NV. Oral mucoadhesive drug delivery systems: A review. Int J Biopharm 2011;2:36-46.

8. Khurana S, Madhav NV, Pranshu T, Mucoadhesive drug delivery: Mechanism and method of evaluation: A review. Int J Pharm Biosci 2011;2:458-64

9. Pathan A, Dev A. Formulation and evaluation of bioadhesion drug delivery system. Pharm Biol Eval 2016;3:377-87.

10. Devireddy SR, Orugonda K, Devireddy V, Pectin AS. A release retardant in gas generating floatable system of nizatidine-preparation and evaluation. J Global Trends Pharm Sci 2017;8:3554-63. 